
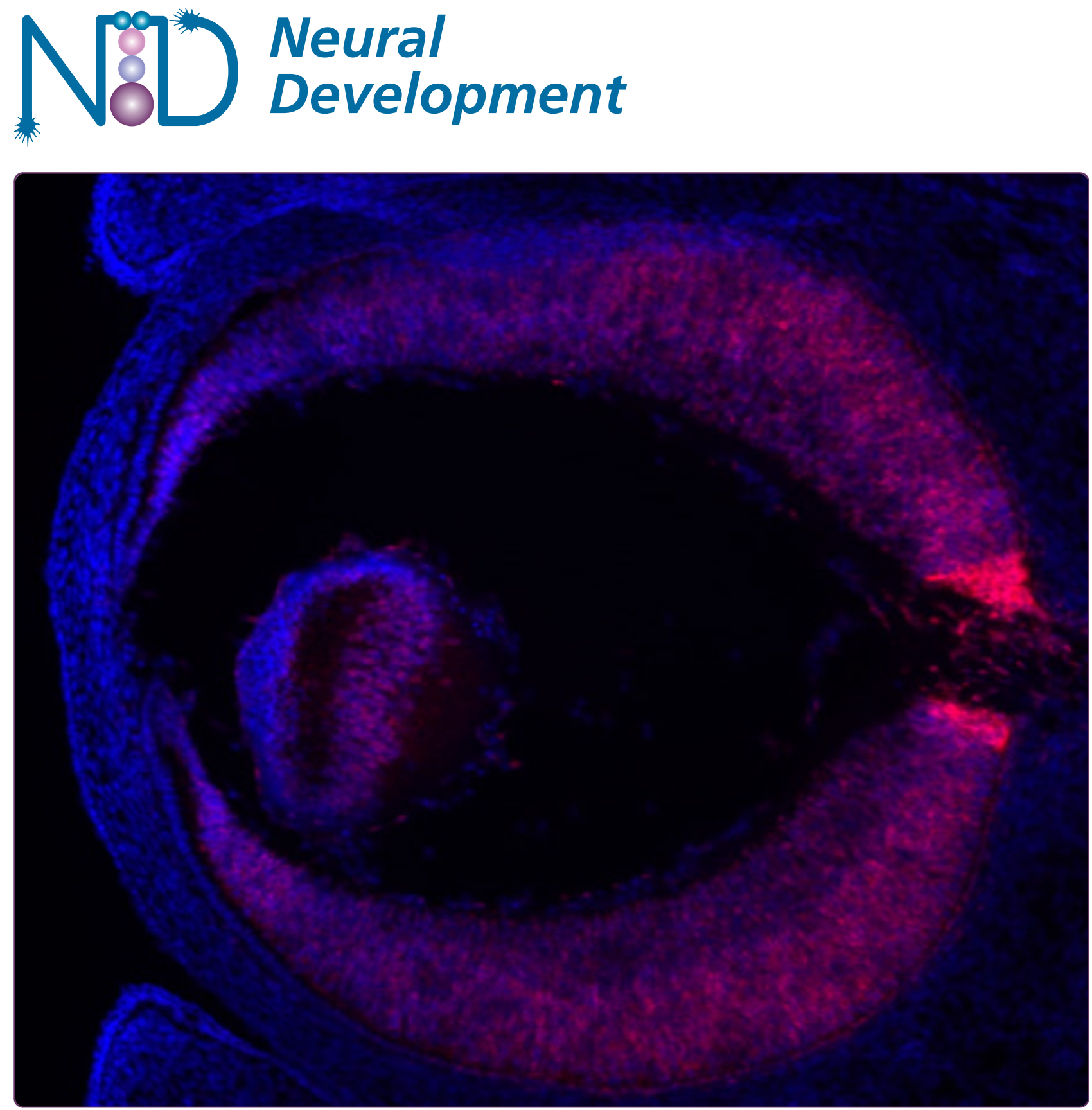

The long noncoding RNA Six 30 S acts in trans to regulate retinal development by modulating Six3 activity

Rapicavoli et al. 


\title{
The long noncoding RNA Six3OS acts in trans to regulate retinal development by modulating Six3 activity
}

Nicole A Rapicavoli ${ }^{1,2}$, Erin M Poth ${ }^{1}$, Heng Zhu ${ }^{3}$ and Seth Blackshaw ${ }^{1 *}$

\begin{abstract}
Background: Thousands of different long non-coding RNAs are expressed during embryonic development, but the function of these molecules remains largely unexplored.

Results: Here we characterize the expression and function of Six3OS, a long non-coding RNA that is transcribed from the distal promoter region of the gene encoding the homeodomain transcription factor Six3. Overexpression and knockdown analysis of Six3OS reveals that it plays an essential role in regulating retinal cell specification. We further observe that Six3OS regulates Six3 activity in developing retina, but does not do so by modulating Six3 expression. Finally, we show that Six3OS binds directly to Ezh2 and Eya family members, indicating that Six3OS can act as a molecular scaffold to recruit histone modification enzymes to Six3 target genes.

Conclusions: Our findings demonstrate a novel mechanism by which promoter-associated long non-coding RNAs can modulate the activity of their associated protein coding genes, and highlight the importance of this diverse class of molecules in the control of neural development.
\end{abstract}

\section{Background}

It has recently become clear that long non-coding RNAs (lncRNAs) comprise a large fraction of the mammalian transcriptome [1]. Much effort has been focused on functional analysis of lncRNAs that are processed into short fragments, such as microRNAs, that regulate expression of protein coding genes via homologous base pairing. However, several thousand mammalian lncRNAs have been identified that span multiple kilobases in length, and in some cases show extensive conservation at the nucleotide level [2-4].

To date, only a small number of lncRNAs have been functionally characterized, although this list is growing rapidly. Some lncRNAs act via antisense base pairing to block gene expression [5-7], but many show no clear sequence overlap with the mRNAs of protein coding genes. Several of these lncRNAs are known instead to

\footnotetext{
* Correspondence: sblack@jhmi.edu

'Department of Neuroscience, Neurology and Ophthalmology, Center for High-Throughput Biology and Institute for Cell Engineering, Johns Hopkins University School of Medicine, 733 N. Broadway Avenue, Baltimore, MD 21287, USA

Full list of author information is available at the end of the article
}

regulate mRNA transcription, acting in cis to regulate heterochromatin formation at nearby genomic loci. The Xist/ Tsix transcripts mediate X-inactivation in placental mammals [8], and Kcnq1ot is important for silencing of the Kcnq locus resulting from parental imprinting [9]. Other lncRNAs regulate transcription of genes that are located great distances away from their own genomic loci. One notable example of such a trans-acting lncRNA is HOTAIR, which is transcribed from within specific Hox gene clusters, but which regulates the expression of Hox genes located on different chromosomes [10,11]. HOTAIR, Kcnq1ot and Xist all mediate their effects by interacting with the Polycomb-repressive complex 2 (PRC2) component Ezh2 (enhancer of zeste homolog 2 (Drosophila)) and modulating histone methylation $[9,11,12]$. Finally, a small number of lncRNAs also directly interact with transcription factors, and potentially function as transcriptional coregulators [13-15]. Although the emerging picture suggests that lncRNAs may play an important and widespread role in regulating mammalian gene expression, a central and still unresolved question is how lncRNAs act in trans to regulate expression of specific target genes without the use of homologous base paring. 
A complex assortment of lncRNAs is expressed in the developing and mature mammalian central nervous system, with the cellular expression patterns of nearly 1 , 000 different lncRNAs having been previously described [16-18]. Many show highly specific expression in specific brain regions and neuronal subtypes and it has been speculated that these lncRNAs may play a critical role in generating and maintaining the great cellular complexity found in the central nervous system $[19,20]$. Although a limited number of intergenic lncRNAs have been found to regulate neural development, their mode of action remains obscure $[21,22]$. Mechanistic insight into the function of one brain-expressed lncRNAs has come from analysis of Evf-2, a lncRNA co-transcribed with the homeodomain factor Dlx6. Evf-2 modulates transcription of $D l x 6$ by recruiting DLX2 and MECP2 to the ultraconserved $e i$ enhancer element that is also transcribed as part of $E v f-2$ itself. The transcribed domain containing the $e i$ sequence is essential for $E v f-2$ to activate expression of $D l x 6$, which has raised the possibility that Evf-2 might regulate $D l x 6$ transcription at least in part through the formation of a RNA-DNA hybrid; this hybrid may in turn facilitate binding of the $e i$ sequence by DLX2 and MECP2 $[14,15]$.

Recent studies have also begun to address the function of long non-coding opposite-strand transcripts (lncOSTs), which are divergently co-transcribed with a broad range of neuronally expressed genes. Over one-third of brainexpressed homeodomain genes possess an associated IncOST, which typically spans the promoter, but not the transcribed region, of the protein coding gene in question $[23,24]$. Since short promoter-associated ncRNAs can regulate expression of nearby protein coding genes [25-27], this has raised the possibility that these lncOSTs might also act in cis to selectively regulate the expression of their associated protein coding gene. However, although lncOSTs comprise a substantial fraction of all brainexpressed lncRNA species, their function has yet to be directly investigated.

In this study, we characterize the molecular function and mechanism of the lncOST Six3OS. Six3OS is co-expressed with the homeodomain factor Six3, a homologue of the Drosophila sine oculis gene [28,29]. Like sine oculis, Six3 plays a critical role in mammalian eye development, regulating both early eye formation and cell specification in the postnatal retina [30,31]. Both Six3 and Six3OS are strongly and selectively expressed in the developing mouse retina and hypothalamus $[23,32,33]$. We use both in vivo overexpression and short hairpin RNA (shRNA)-mediated knockdown analysis to analyze whether gain or loss of function of Six3OS results in altered differentiation of specific retinal cell subtypes. We also examine whether Six3OS acts cooperatively with Six3 to regulate retinal differentiation, but find that Six3OS does not regulate Six3 expression levels. Finally, we provide evidence that Six3OS can directly bind both to known transcriptional coregulators of Six3 and to histone modification enzymes, thereby functioning as an RNA-based transcriptional scaffold. These results demonstrate the mechanism by which this diverse class of molecules regulates cell specification during development.

\section{Results}

\section{Genomic organization of Six3 and Six3OS}

To determine which regions of Six3OS to target for functional analysis, we first examined the genomic organization and evolutionary conservation of this lncOST using publicly available cDNA and genomic sequence. As previously reported, we found that $\operatorname{Six} 3 O S$ is alternatively spliced in both mouse and human [23], although Six3OSlike transcripts were not identified in any other vertebrate species examined (data not shown). To determine which sequences to target for overexpression and knockdown, we aligned these sequences and observed that the putative full-length mouse cDNA BC065087 contains the exon sequences shared by all alternative splice forms of Six3OS (Figure 1, light grey bars). Two of these exons are adjacent to alternatively spliced exons of the human Six3OS orthologue, which lie within intronic regions of the mouse transcript (Figure 1, dark grey bars). This cDNA corresponds to the most abundant isoform in neonatal retina as measured by serial analysis of gene expression (SAGE) tag abundance [32], and also matches the 4.5-kb isoform of Six3OS, previously reported to be the most abundant isoform expressed in embryonic brain [33]. We therefore selected this cDNA for analysis by overexpression.

\section{Cellular expression pattern of Six3OS}

To determine if Six3 and Six3OS are co-expressed in retinal progenitors, as had been previously suggested $[23,32,33]$, we performed chromogenic in situ hybridization (ISH) on sections of embryonic day (E)16.5 and postnatal day $(\mathrm{P}) 0.5$ retina (Figure $2 \mathrm{~A}-\mathrm{H})$. We observed that Six3 and Six3OS are co-expressed in both retinal progenitor cells and newly post-mitotic cells of the inner neuroblastic layer. Additionally, Six3OS is expressed in the developing lens (Figure 2C), while Six3 expression is concentrated at the interface of the inner and outer neuroblastic layers (Figure 2B) at E16.5. At P0.5, Six3OS expression appears to be more concentrated in the outer neuroblastic layer when compared to Six3, which is primarily found in the inner neuroblastic layer (Figure $2 \mathrm{H}$ ). The differences at the interface between these layers are more difficult to discern at P0.5, due to the increased expression of Six3OS in the outer neuroblastic layer (Figure $2 \mathrm{E}-\mathrm{H})$. To determine the subcellular expression pattern of Six3OS during development, we performed 


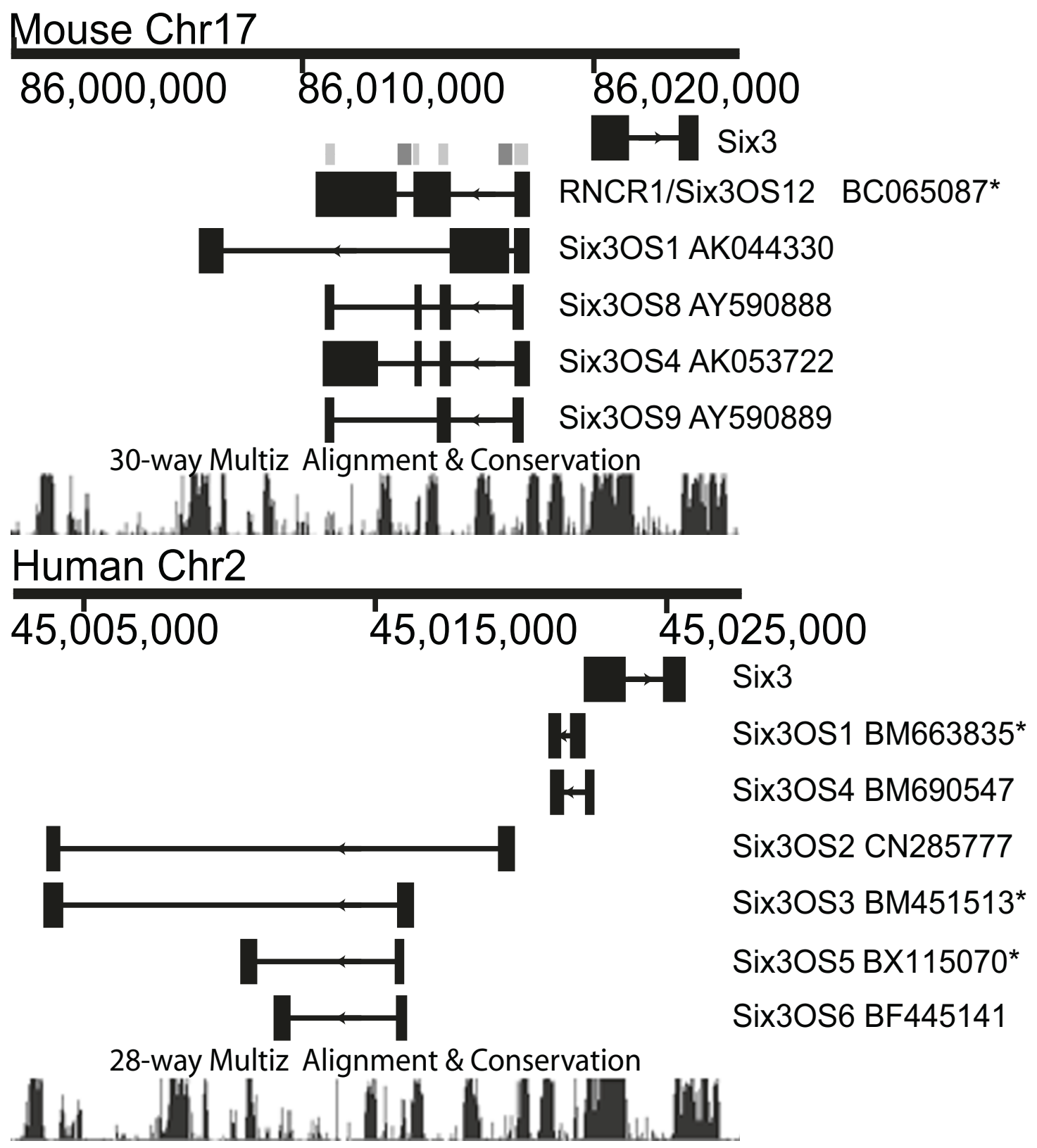

Figure 1 Genomic structure and evolutionary conservation of Six3 and Six3OS. Schematic drawing showing conservation of human and mouse Six3 and Six3OS genomic structure. Light grey bars show where the predominant Six3OS mouse and human forms overlap. Dark grey bars indicate where mouse Six3OS is adjacent to conserved regions. Conservation is plotted using the PhastCons program [47]. An asterisk indicates the cRNA probes that were hybridized to the protein microarray in Figure 6.

fluorescent ISH (FISH) with a probe for Six3OS at E14.5, at which point prominent expression in progenitor cells of the outer neuroblastic layer is seen (Figure 2I). Interestingly, though most Six3OS RNA is localized in the cytoplasm of retinal progenitors at this stage, some Six3OS RNA is also associated with nuclear DNA (Figure 2I, J). This subcellular distribution has also been noted for the lncRNA Evf-2 [14]. Using FISH in conjunction with immunostaining for the cytoplasmic ribosomal protein S6, we observed that the Six3OS transcript is also found in the nucleus and cytoplasm when expressed in transfected HeLa cells (Additional file 1).

\section{Overexpression and knockdown of Six3 and Six3OS}

Since Six3OS was coexpressed with Six3 in retinal progenitors, we hypothesized that Six3OS might regulate the expression and/or activity of Six3 in developing retina. To determine if this was indeed the case, we employed 


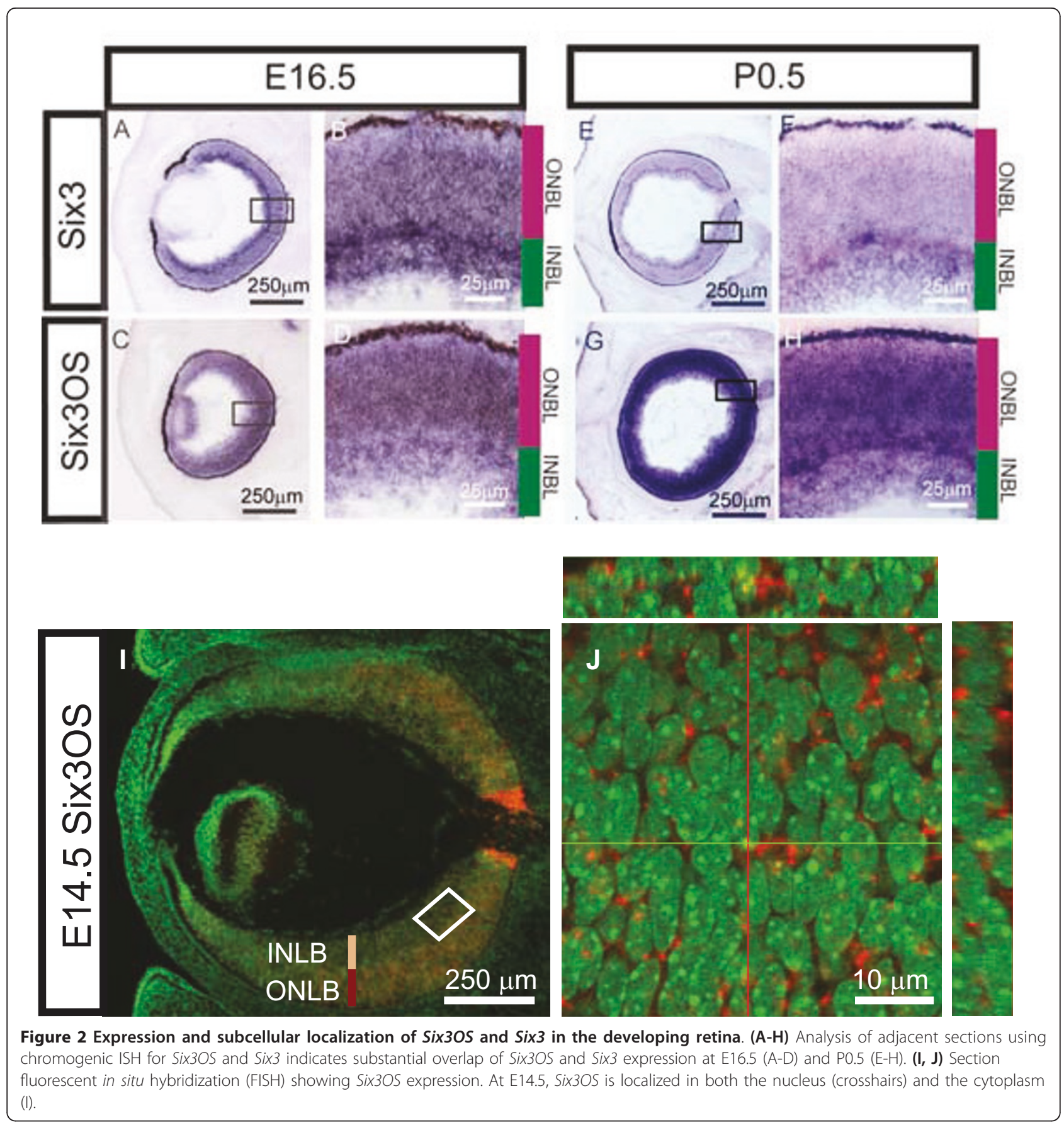

in vivo electroporation of neonatal (P0.5) mice to determine whether overexpression and knockdown of Six3OS phenocopied the effects of overexpression and knockdown of Six3. For overexpression of Six3OS, we used full-length cDNAs corresponding to BC065087 (Figure 1) cloned into the pCAG plasmid [34]. Upon transfection into HeLa cells, robust Six3OS expression was confirmed by FISH (Additional file 1). To visualize electroporated cells, all constructs were co-electroporated with plasmids expressing green fluorescent protein (GFP) from the same CAG promoter.

We observed that overexpression of $1 \mu \mathrm{g}$ of Six3OS resulted in no significant change in any major retinal cell type, and section immunohistochemistry revealed that electroporated cells showed grossly normal morphology (Figure 3B, C, white arrowheads). However, when dissociated cell preparations were examined, a significant decrease $(P<0.05)$ in the fraction of 


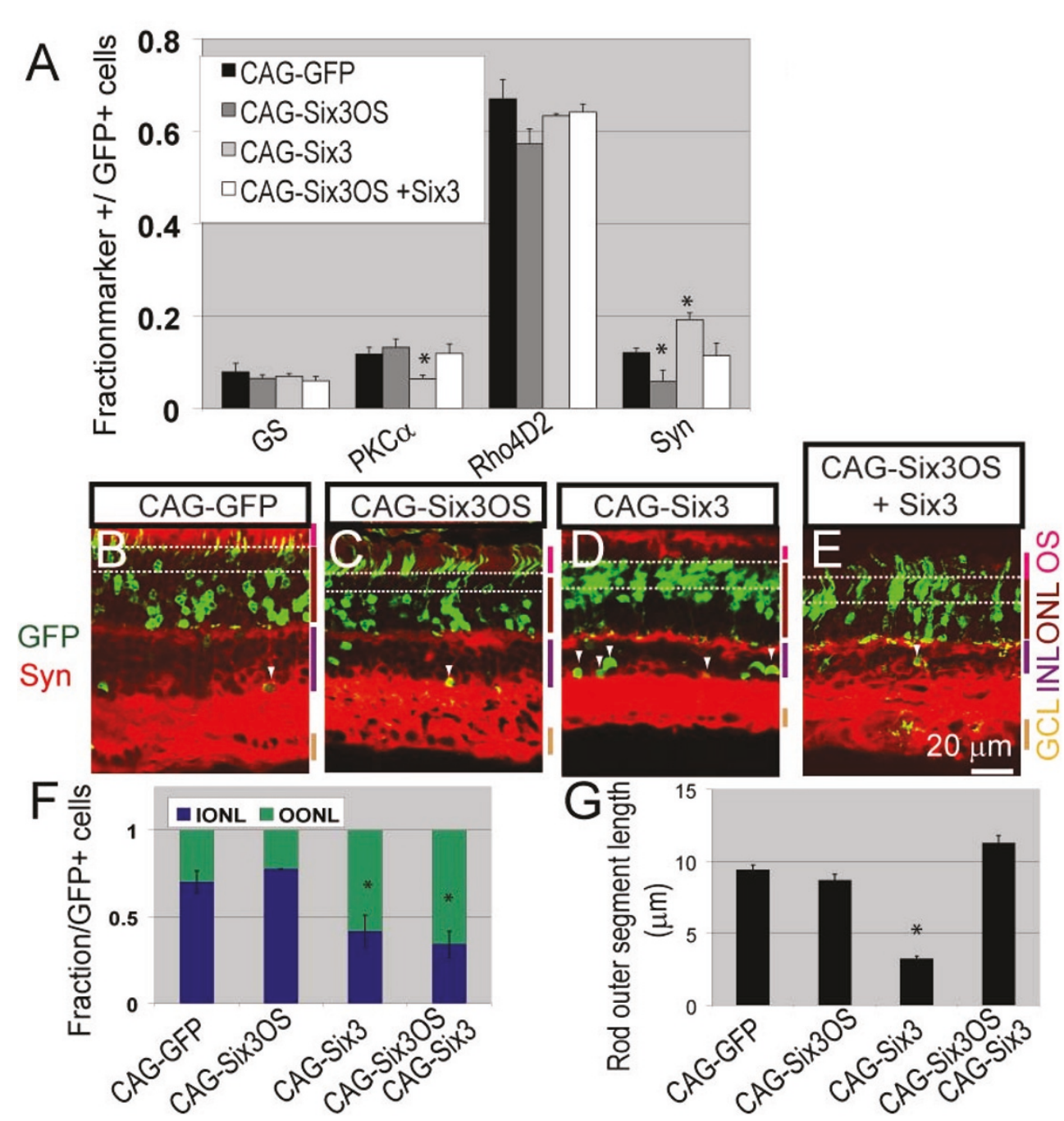

Figure 3 Overexpression of Six3OS in developing retina inhibits changes in cell fate and photoreceptor morphology observed following Six3 overexpression. (A) Electroporation of CAG-Six3 led to an increase in the fraction of GFP-positive cells expressing the amacrine cell marker syntaxin and a decrease in cells expressing the rod bipolar marker PKC $\alpha$, CAG-Six3OS led to a decrease in syntaxinpositive cells, and co-expression led to a cell composition that was indistinguishable from CAG-GFP controls. ${ }^{*} P<0.05$. (B-E) Section immunohistochemistry of retinas electroporated with CAG-GFP, CAG-Six3OS, CAG-Six3 or both CAG-Six3OS and CAG-Six3. White dashed lines define the outer third of the outer nuclear layer (OONL). Syntaxin (red) is co-immunostained with GFP (green). (C) No obvious difference is observed in either amacrine cell number or morphology (white arrowheads) in retinas electroporated with CAG-Six3OS relative to CAG-GFP controls or in the fraction of the cells in the OONL. (D) An increase in amacrine cell number and in the number of cells in the OONL and a decrease in outer segment length is observed in the case of Six3. (E) An increase in the number of cells in the OONL is observed, but no difference in amacrine cell number or outer segment length is observed from controls following co-electroporation of CAG-Six3 and CAGSix3OS. GCL, ganglion cell layer; INL, inner nuclear layer; ONL, outer nuclear layer; OS, outer segment.. (F) Laminar position of cells within the OONL. Electroporation of CAG-Six3 leads to a shift of rod photoreceptor cell bodies to the OONL, and this effect is not affected by coelectroporation of CAG-Six3OS (white dashed lines in B-E). (G) Rod photoreceptors electroporated with CAG-Six3 show substantially shorter outer segments and this effect is reversed by co-electroporation with CAG-Six3OS. Cell type specific markers used: rhodopsin (Rho4D2), rod photoreceptors; glutamine synthetase (GS), Muller glia; protein kinase C alpha (PKC $\alpha$ ), rod bipolar cells; syntaxin (Syn), amacrine cells.

GFP-positive cells expressing amacrine cell-specific marker syntaxin was observed relative to cells electroporated with the GFP control vector at P21 (Figure 3A). Since Six3OS overexpression did not alter the fraction of GFPpositive cells with amacrine-like morphology and laminar position, we conclude that Six3OS does not inhibit amacrine cell specification. The reduction in syntaxin expression seen following CAG-Six3OS electroporation thus reflects a quantitative reduction in syntaxin levels or possibly reflects reduced adhesion of Six3OSexpressing amacrine cells following dissociation for immunocytochemistry. 
We next tested the effects of overexpression of pCAGSix3 using in vivo electroporation. Upon electroporation, expression of Six3 was confirmed by section immunohistochemistry. Cell fate specification in the postnatal retina is highly sensitive to Six3 dosage, and both gain and loss of function of Six3 have been reported to result in similar defects in bipolar cell and photoreceptor development [30]. We observed that electroporation of $1 \mu \mathrm{g}$ of pCAG-Six3 led to a reduction in the number of rod bipolar cells, and detected an increase in the fraction of GFP-positive amacrine cells by P21 $(P<0.05$; Figure $3 \mathrm{~A}, \mathrm{D})$. The length of the outer segments of GFP-positive rod photoreceptors was also decreased $(P<0.05$; Figure 3D, G). Finally, we observed that the cell bodies of the Six3 electroporated photoreceptor cells were primarily located in the outer third of the outer nuclear layer $(P<0.05$; Figure $3 \mathrm{D}$, white dashed line, and $3 \mathrm{~F}$ ), in contrast to photoreceptors electroporated with control vector, which were distributed throughout the outer nuclear layer.

We then analyzed the effects of loss of function of Six3OS and Six3. To this end, we first tested shRNAs for their ability to reduce expression of endogenous Six3 and Six3OS expression by in vivo electroporation of P0.5 retina. Reduction in expression of the target gene was determined by analyzing expression of either Six3 protein or Six3OS RNA dissociated GFP-positive cells. For both Six3 and Six3OS, individual shRNA constructs were identified that resulted in a substantial reduction in the average fluorescence intensity in either Six3 protein or Six3OS RNA in GFP-positive cells (Additional file 2).

A significant decrease in the fraction of protein kinase $C$ $\alpha$ (PKC $\alpha$ ) positive rod bipolar cells was observed at P21 following electroporation of either $1 \mu \mathrm{g}$ of Six3 shRNA construct or $1 \mu \mathrm{g}$ of $\operatorname{Six} 3 \mathrm{OS}$ shRNA $(P<0.05$; Figure $4 \mathrm{~A})$, reminiscent of effects of retroviral overexpression of a dominant-negative mutant form of Six3 [30]. The fraction of glutamine synthetase-positive Muller glia was also increased $(P<0.05$; Figure $4 \mathrm{~A})$. Section immunohistochemistry confirmed an increase in glutamine synthetasepositive cells with Muller glia-like morphology, at the expense of cells expressing the bipolar cell marker CHX10 and demonstrating bipolar-like morphology (Figure 4B-D,

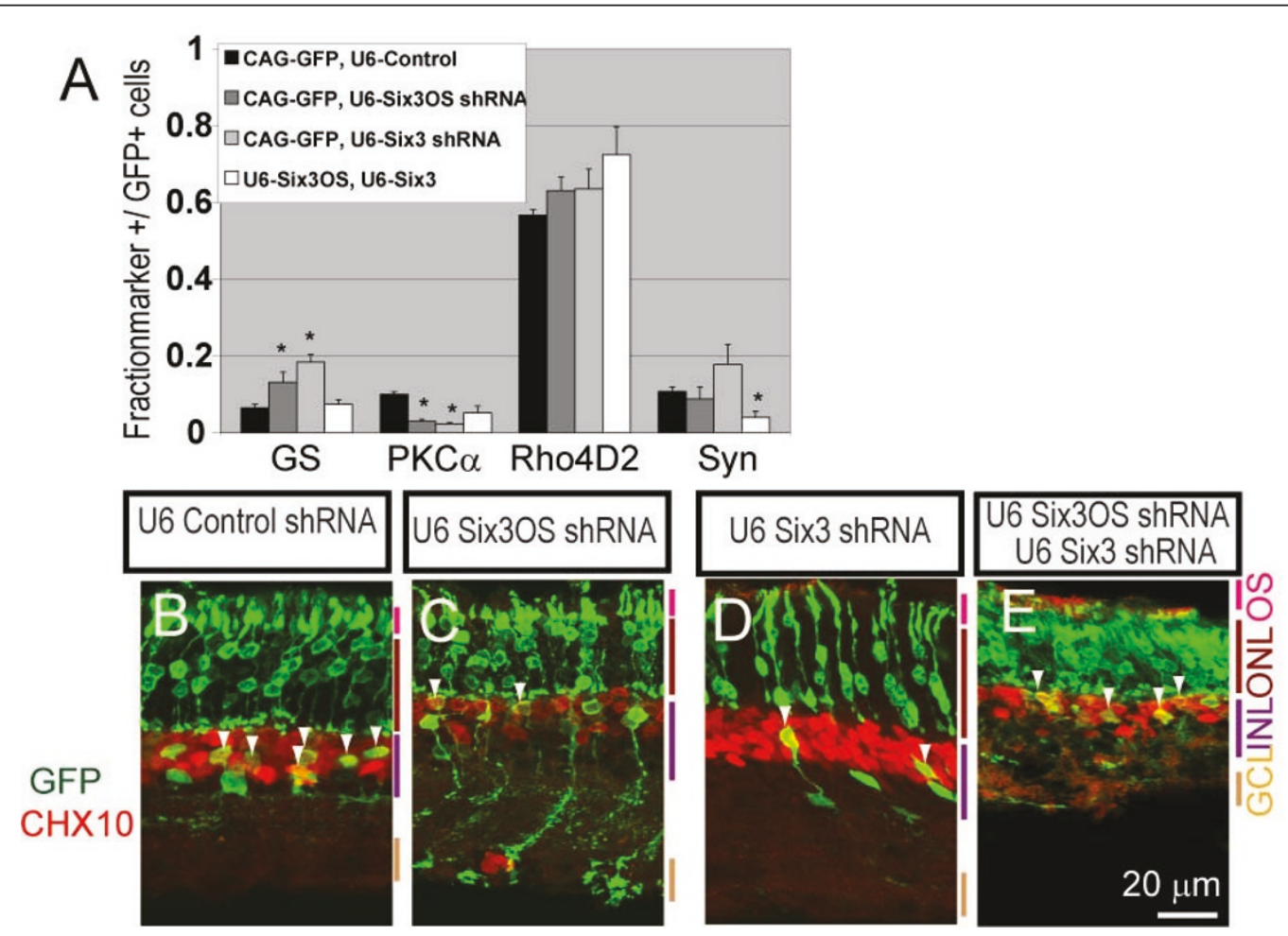

Figure 4 shRNA-mediated knockdown of Six3 and Six3OS in the developing retina alters bipolar cell and Muller glial development. (A) Six3 knockdown and Six3OS knockdown both lead to an increase in Muller glia and a decrease in rod bipolar cells as measured by immunostaining of dissociated electroporated retinal cells. Simultaneous knockdown of both Six3 and Six3OS resulted in a normal number of rod bipolar and Muller glia, but a decrease in syntaxin (Syn)-positive amacrine cells was observed. ${ }^{*} P<0.05$. GS, glutamine synthetase. (B-E) Section immunohistochemistry demonstrates a decrease in GFP-positive bipolar cells following knockdown of either Six3OS or Six3, but not both in combination (white arrowheads). Chx10 (ceh-10 homeodomain containing homolog (C. elegans)) was used as pan-bipolar cell marker. GCL, ganglion cell layer; INL, inner nuclear layer; ONL, outer nuclear layer; OS, outer segment. 
white arrowheads). To further confirm that knockdown experiments did indeed result in a selective loss of function of Six3OS, we also inhibited Six3OS function by overexpression of Six3OS-IRES-GFP. Fusion of IRES-GFP to lncRNAs results in a mislocalization of lncRNAs to the ribosome, and can produce dominant negative phenotypes when overexpressed [22]. When this is performed, we observed a reduction in rod bipolar markers and an increase in Muller markers, phenocopying the effects of Six3OS knockdown (data not shown).

\section{Simultaneous overexpression and knockdown of Six 3 and Six30S demonstrates non-additive effects on retinal differentiation}

Having observed that loss of function of Six3 and Six3OS resulted in similar phenotypes in developing retina, we next investigated whether these two genes acted cooperatively or independently to regulate retinal differentiation. We first used in vivo electroporation to overexpress $1 \mu \mathrm{g}$ of both the Six 3 and Six3OS constructs simultaneously in P0.5 retina. We observed that co-expression of Six3 and Six3OS resulted in a normal cell fate phenotype (Figure 3A). The length of GFP-positive rod photoreceptor outer segments was indistinguishable from controls (Figure 3B, E, G). However, the cell bodies of the electroporated photoreceptor cells were primarily located in the outer third of the outer nuclear layer $(P<0.05$; Figure $3 B, E$, white dashed line, and $3 \mathrm{~F}$ ). We thus concluded that overexpression of Six3OS was largely able to reverse the cellular phenotypes observed following overexpression of Six3.

As a follow up to these experiments, we simultaneously reduced expression of Six3 and Six3OS by co-electroporating $1 \mu \mathrm{g}$ of the Six3 shRNA construct and $1 \mu \mathrm{g}$ of Six3OS shRNA construct. We observed that simultaneous knockdown of both Six3 and Six3OS resulted in a normal number of bipolar cells and Muller glia. However, we observed a significant decrease in the fraction of GFPpositive amacrine cells, which was not observed following electroporation of either the Six3 or Six3OS shRNA alone $(P<0.05$; Figure $4 \mathrm{~A}, \mathrm{E})$. These data show a nonadditive effect of simultaneous loss of function of both Six3 and Six3OS, and show that these genes functionally interact to regulate retinal differentiation.

Lastly, we directly investigated the functional relationship between Six3 and Six3OS in vivo by simultaneously overexpressing Six3 and knocking down Six3OS, and vice versa. When we co-electroporated $1 \mu \mathrm{g}$ of CAG-Six3 with $1 \mu \mathrm{g}$ of Six3OS shRNA, we found that Six3 overexpression fully rescued the Six3OS knockdown phenotype. Furthermore, loss of function of Six3OS fully eliminated the effects of Six3 overexpression. No differences in the composition of GFP-positive cells were observed when compared to controls (Figure 5A). Both the morphology and distribution of the cells within the retina were normal
(Figure 5C, D; Additional file 3A), and the rod photoreceptor outer segment length was normal (Additional file 3B). We conclude that Six3OS is required for many of the effects on retinal differentiation that result from Six3 overexpression.

In contrast, when $1 \mu \mathrm{g}$ of CAG-Six3OS was co-electroporated with $1 \mu \mathrm{g}$ of Six3 shRNA, we observed an increase in glutamine synthetase-positive cells with Muller glia-like morphology $(P<0.05$; Figure $5 \mathrm{~B})$ and a decrease in PKC $\alpha$-positive and $\mathrm{CHX10-positive} \mathrm{bipolar}$ cells $(P<0.05$; Figure $5 \mathrm{~B}, \mathrm{C}, \mathrm{E})$ when compared to controls. Additionally, a decrease in cells expressing the amacrine cell-specific marker syntaxin was observed $(P<0.05$; Figure 5B). These retinas, however, do not show any change in the number of GFP-positive cells with amacrine cell-like morphology. We therefore conclude that, as is the case when Six3OS alone was overexpressed, Six3OS overexpression in conjunction with knockdown of Six3 reduces syntaxin expression without otherwise affecting amacrine cell differentiation (Figure $5 \mathrm{~B}, \mathrm{E})$. The phenotype seen here is the sum of the phenotypes seen following Six3OS overexpression and Six3 knockdown, and stands in contrast to the non-additive phenotype seen when Six3OS and Six3 are both simultaneously knocked down (Additional file 4). We thus conclude that the phenotype observed following Six3OS overexpression is not affected by Six 3 loss of function, and that Six3OS may also regulate syntaxin expression through a Six3-independent mechanism.

\section{Six3OS does not directly regulate Six3 protein levels}

Although these data suggest that Six 30 S regulates Six3 function in developing retina, they do not directly address the molecular mechanism by which Six3OS is able to do so. A number of studies have suggested that both promoter and enhancer-associated lncRNAs can act in cis to regulate expression levels of nearby protein-coding genes [14,25-27,35,36]. To investigate whether Six3OS might be regulating Six3 function by a similar mechanism, we overexpressed and knocked down expression of Six3OS at P0.5 in retina, and quantified the level of Six3 protein in GFPpositive cells at P5.5. We did not observe any change in Six3 protein levels following either overexpression or knockdown of Six3OS (Additional file 5A, B). Furthermore, we tested whether Six3OS could regulate Six3dependent regulation of a reporter construct derived from the sequence of the mouse Six 3 promoter, which was previously shown to be negatively regulated by Six3 [30]. To determine if Six3OS modulates Six3-mediated auto-repression, CAG-Six3OS was cotransfected with the CMV-Six3 and the Six3-pro luciferase vector. As previously reported, overexpression of $\operatorname{Six} 3$ represses this reporter construct when tested in NIH3T3 cells. However, Six3OS overexpression had no effect on Six3-mediated auto-repression 


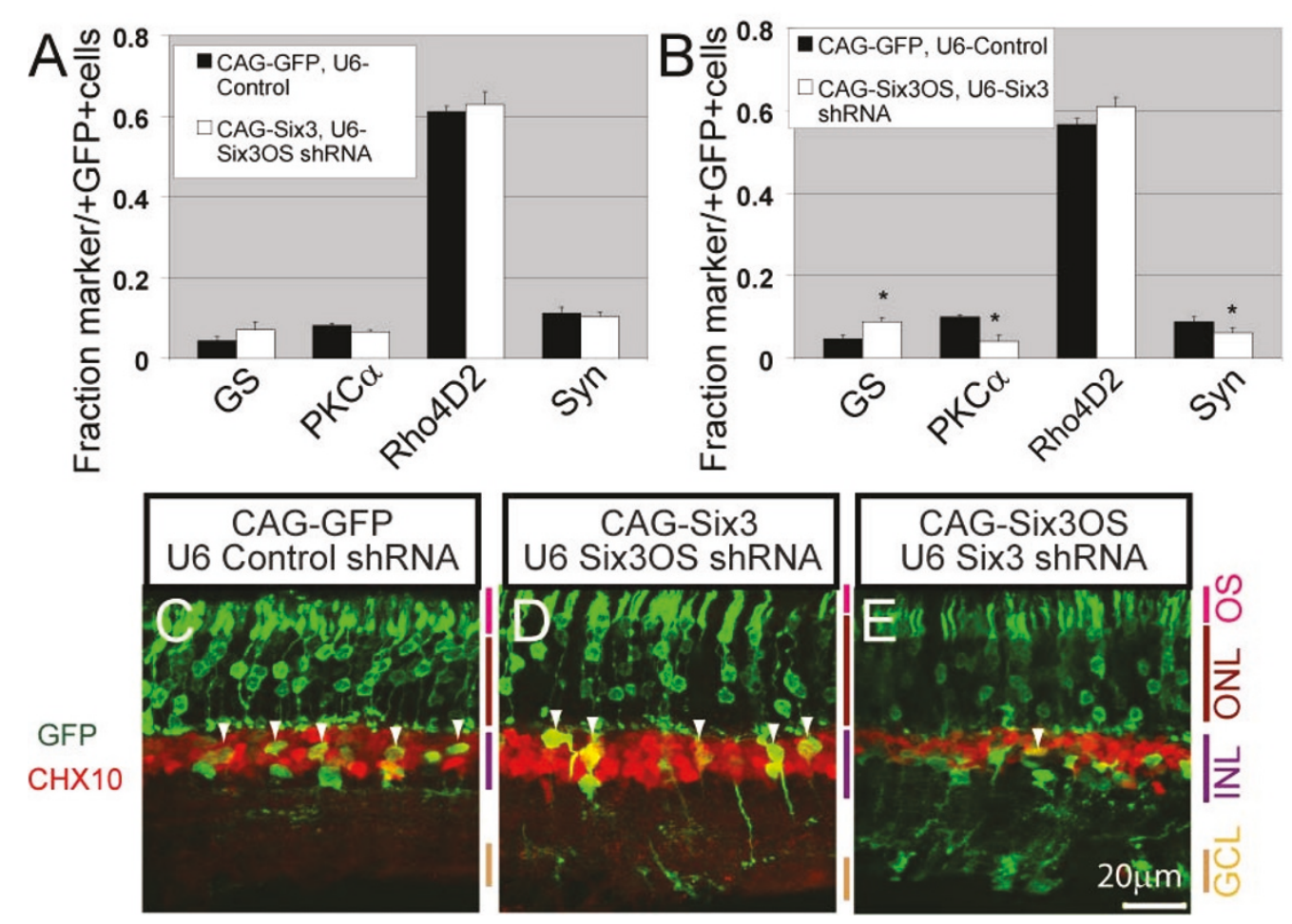

Figure 5 Six 3 overexpression rescues the Six3OS knockdown phenotype whereas Six3OS overexpression is not sufficient to rescue the loss of Six3. (A) Six3OS knockdown combined with Six3 overexpression led to a cell type distribution indistinguishable from cells electroporated with control constructs when tested by immunostaining of dissociated electroporated retinal cells. (B) Six3 knockdown combined with Six3OS overexpression led to an increase in Muller glia and a decrease in rod bipolar cells and a decrease in syntaxin (Syn)-positive amacrine cells. GS, glutamine synthetase. (C-E) Section immunohistochemistry of retinas confirm a distribution of GFP-positive cells that is indistinguishable from controls when Six3OS knockdown is combined with Six3 overexpression, while Six3 knockdown and Six3OS overexpression led to a decrease in bipolar cells (F, white arrowheads). GCL, ganglion cell layer; INL, inner nuclear layer; ONL, outer nuclear layer; OS, outer segment.

(Additional file 6). Although 14 additional human and mouse cell lines were tested, no Six3OS-dependent effects on Six3-mediated autorepression could be detected (data not shown). We conclude that transcription of Six3 mRNA is not regulated by Six3OS. Instead Six3OS RNA likely modulates the ability of Six 3 protein to activate or repress expression of its target genes in developing retinal cells.

\section{Ezh2 and Eya1/3/4 directly bind Six3OS}

To identify proteins that directly bind Six3OS, Cy5labeled Six3OS RNA was used to probe human protein microarrays [37]. Mouse Six3OS and three human splice variants of Six3OS were transcribed in vitro and labeled with Cy5, and antisense cRNAs for these same transcripts were hybridized in parallel as negative controls. A total of five proteins that specifically and selectively interact with both the mouse and human forms of Six3OS were thus identified. We found that both human and mouse Six3OS selectively interact with Eya1, encoded by a homologue of the eyes absent gene of Drosophila. In addition, Six $3 O S$ directly binds to the chromatin remodeling enzyme subunits Smarce1 and Ezh2, as well as Eno1 and Ppp5c (Additional file 7). Members of the Eya protein family have been previously shown to interact with Six family proteins [38], but Eya1 is not expressed in the mouse neuroretina [32]. Therefore, we also performed RNA immunoprecipitation (RIP) experiments on Eya3 and Eya4, which are both robustly expressed in embryonic retina.

To test whether Ezh2 and Eya family members interact with mouse Six3OS in vivo, co-immunoprecipitation experiments were performed in HEK 293T cells overexpressing V5-tagged Eya1, Eya3, Eya4 and Ezh2. Expression and immunoprecipitation of V5-tagged protein was verified by immunoblot (Additional file 8 ). We confirmed that mouse Six3OS RNA selectively interacts with each of these proteins using RIP (Figure 6), and conclude that these proteins interact with Six3OS in transfected HEK 293T cells. To confirm that Six3OS interacts with Eya family members and Ezh2 specifically, we examined whether Six3OS interacts directly with Six3 protein by RIP and found that Six3OS and Six 3 do not interact in transfected HEK 293T cells (data not 


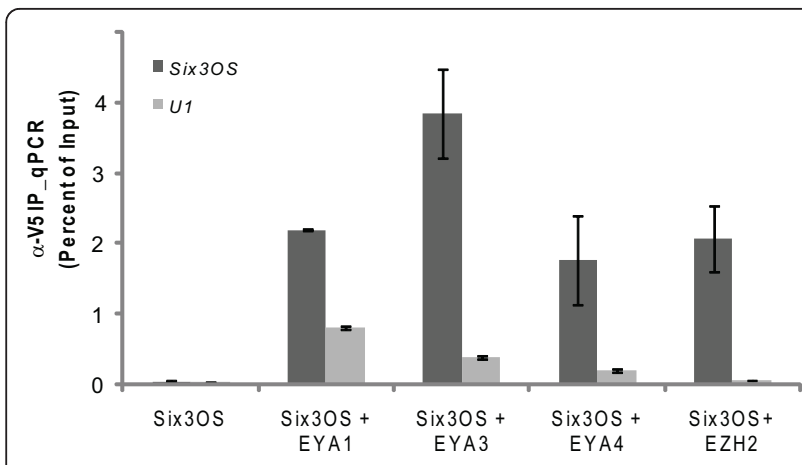

Figure 6 Six3OS-protein interactions detected via protein microarray. $\alpha$ V5-RIP specifically retrieves Eya1-V5, Eya3-V5, Eya4-V5 and Ezh2-V5 bound to Six3OS RNA but not U1 small nuclear RNA. Mean \pm standard deviation, $n=3$, relative to input is shown.

shown). This suggests that Six3OS regulates Six3 function by facilitating interaction between Eya proteins and chromatin-modifying enzyme complexes.

\section{Discussion}

\section{Six 30 S and Six 3 modulate retinal cell specification and} differentiation

Our findings demonstrate that both gain and loss of function of Six3OS and Six3 affect retinal differentiation (Additional file 4). Knockdown of Six3OS resulted in a decrease in the fraction of bipolar cells and an increase in Muller glia in electroporated cells. An identical phenotype was observed following knockdown of Six3 (Figure 4). Knockdown of either Six3OS or Six3 phenocopies the effect of retroviral overexpression of a dominant-negative form of Six3 in neonatal retina, where a substantial decrease in bipolar cells was also seen [30].

In contrast, overexpression of either Six3 or Six3OS alone produced very different phenotypes. Six3OS overexpression resulted in a reduction in syntaxin staining in electroporated amacrine cells, but did not alter the morphology or laminar position of electroporated cells. On the other hand, Six3 overexpression, like Six3 loss of function, resulted in a dramatic reduction in the number of bipolar cells (Figure 3A), and also resulted in decreased rod photoreceptor outer segment length at P21 (Figure 3D, G). These effects were previously reported following retroviral-mediated overexpression of Six3 [30]. Interestingly, we also observed phenotypes that were not reported in this previous study, such as an increase in amacrine cells. A number of technical differences between these two experiments may account for these differences, most notably the fact that electroporation-mediated overexpression typically results in much higher levels of construct expression in developing retina than does retroviral transduction [34].
Six30S regulates Six3 activity in developing retina, but does not regulate Six 3 expression levels

If Six 3 and Six3OS act independently to control retinal cell specification, we would expect to observe purely additive phenotypes when their activities are both altered. Strikingly, when both Six3OS and Six3 were overexpressed simultaneously, we no longer observed the cellular phenotypes that resulted from overexpression of Six3 alone. Simultaneous knockdown of both Six3OS and Six3 also showed non-additive effects. The loss of bipolar cells and increase in Muller glia, which was seen following knockdown of each gene individually, were not observed when expression of both Six3 and Six3OS was reduced. Instead, a decrease in amacrine cells was observed, which was a phenotype not observed when each individual gene was knocked down. These non-additive phenotypes demonstrate an epistatic relationship between Six3 and Six3OS, and imply that they functionally interact to regulate retinal differentiation.

Having demonstrated that Six3 and Six3OS interact to regulate retinal differentiation, we next investigated whether defects in Six3 could be rescued by overexpression of Six3OS, and vice versa. When Six3 is overexpressed but Six3OS is knocked down, none of the phenotypes normally seen following either Six3 overexpression alone or Six3OS knockdown alone were observed (Figure 5A, C-D). These data indicate that loss of function of Six3OS suppresses the effects of both gain and loss of function of Six3. However, simultaneous overexpression of Six3OS and knockdown of Six3 resulted in a purely additive phenotype that was the sum of the effects of Six 3 knockdown and Six3OS overexpression. These findings suggest that Six3OS acts to regulate Six3 activity, since overexpression of Six3 can rescue the effects of Six3OS knockdown, but not vice versa. As Six3OS overexpression leads to a reduction in syntaxin expression even following Six3 knockdown, this implies that Six3OS may also regulate retinal differentiation through a Six3-independent mechanism, although this remains to be characterized further.

Since both promoter- and enhancer-associated ncRNAs have been previously thought to act in cis to selectively regulate expression of nearby protein coding genes [36,39], our finding that Six3OS did not regulate Six3 expression came as something of a surprise. Our finding that Six $3 O S$ acts in trans to regulate retinal differentiation was supported by several lines of evidence. First, by the finding that the activity of Six 3 expressed from the CAG promoter can be modulated by overexpression or knockdown of Six3OS (Figure 5). Second, we have directly demonstrated that neither overexpression nor knockdown of Six3OS has any detectable effect on Six3 expression in retina, nor does Six3OS have an effect on Six3-dependent autorepression when measured by 
luciferase analysis in transfected tissue culture cells. These data imply that Six3OS and perhaps other lncOSTs do not regulate transcription of their associated protein coding genes, but instead act in trans to regulate the activity directly via protein-RNA interactions. This mechanism may not hold true for all promoter-associated IncRNAs, however, and each will have to be characterized independently to determine its mechanism of action.

\section{Six30S selectively interacts with Eya family members and Ezh2}

While these data demonstrate a functional relationship between Six3OS and Six3, they still leave the precise mechanism by which Six3OS regulates Six3 activity unresolved. Our finding that both human and mouse isoforms of Six3OS interact with multiple different members of the eyes absent protein family demonstrates how this might occur in vivo. The eyes absent (eya) gene and its mammalian homologues encode protein tyrosine phosphatases that function as transcriptional coregulators. Eya binds directly to sine oculis, and acts in conjunction with sine oculis in controlling eye field specification in Drosophila $[28,29]$. We also observe that Six $3 O S$ directly binds the PRC2 subunit Ezh2, and also possibly the BAF57 subunit Smarce1. Additional confirmation that Six3OS interacts with Ezh2 in vivo comes from a recent study of polycomb-associated RNAs, which found that Six3OS was coprecipitated with PRC2 in embryonic stem cells [40]. We propose that Six3OS can modulate the expression of Six 3 target genes without necessarily regulating expression of Six3 itself by acting as a transcriptional scaffold. When Six3 directs the Six3-Eya complex to bind to specific genomic target sequences, Six3OS may thus act as a transcriptional scaffold, recruiting histone modifying enzyme complexes to regulate expression of Six 3 target genes. Although trans-acting lncRNAs have previously been found to regulate gene expression through recruitment of the Ezh2-containing PRC2 histone methyltransferase complex, their action is restricted to a small subset of target genes, and the mechanism by which this occurs is unknown [11]. Our findings point towards a plausible mechanism by which this could occur. However, in the absence of RNA-IP data that clearly demonstrate interaction of Six3OS with both Eya proteins and Six3 in developing retina, other potential mechanisms of action of Six3OS remain plausible.

Several unresolved questions remain, the most obvious being which Eya subtype is the most relevant target of Six3OS in vivo. Eya1 is known to bind Six 3 both in vitro and in transfected tissue culture cells [41], although the co-expression of Six 3 and Eya1 is limited to the ciliary margin and lens [42]. Eya2, Eya3 and Eya4, however, are all co-expressed with Six3 and Six3OS in both the developing retina and in other forebrain regions [42]. Eya4 and Six3 have been demonstrated to interact in a study of holoprosencephaly, indicating that Eya4 may be the functional bridge between Six 3 and Six3OS in the developing ventral forebrain [43]. Our findings indicate that Six3OS may also regulate retinal differentiation by Six3independent mechanisms. Since Eya family members can interact with other classes of transcription factors, including Hox and Tlx family members [44], this suggests that Six3OS might also modulate the expression of genes regulated by these transcription factors.

Many homeodomain transcription factors that are essential for central nervous system development possess an associated lncOST, including Pax6, Rax, Vax2 and Six6 $[23,45]$. Each of these proteins exhibits complex and dynamic expression during development, and their expression patterns often diverge considerably from those of their associated lncOST. Although their target sequences are present in all cells, the genes that are directly regulated by each protein can vary considerably, both at different developmental stages and in different cell types. Models that explain how this context-dependent regulation of transcription factor activity occurs have typically emphasized combinatorial regulation by other proteins, or celland stage-specific epigenetic modifications. Our finding that lncOSTs can modulate the activity of their associated transcription factors lends an additional layer of complexity to these models, and suggests that this diverse class of molecules may play a critical function in generation of cell subtype diversity within the developing central nervous system.

\section{Materials and methods \\ Animals}

Pregnant CD-1 mice were purchased from Charles River Breeding Laboratories, Wilmington, MA, USA. Animal experiments were approved by the Johns Hopkins University Institutional Animal Care and Use Committee.

\section{In vivo electroporation}

In vivo electroporation of mouse retina was performed as described [34]. Retinas were electroporated at P0.5. Dissociated cells and section immunohistochemistry data shown here were performed at P21. Error bars represent \pm standard error of the mean for at least three independent electroporated retinas. A two-tailed Students $t$-test was performed to determine the $P$-value. Control and experimental constructs were co-electroporated with 0.2 $\mu \mathrm{g}$ of pCAG-GFP to readily visualize electroporated cells by GFP [34]. For overexpression experiments, $1 \mu \mathrm{g}$ of pCAG-GFP was injected with either $1 \mu \mathrm{g}$ of pCAG-Six 3 or $1 \mu \mathrm{g}$ of CAG-Six3OS. For simultaneous overexpression of Six3 and Six3OS, retinas were electroporated with $1 \mu \mathrm{g}$ of pCAG-Six3 and $1 \mu \mathrm{g}$ of CAG-Six3OS. For knockdown of Six 3 and Six3OS, $1 \mu \mathrm{g}$ of U6-control was injected with 
either $1 \mu \mathrm{g}$ of U6-Six3 or $1 \mu \mathrm{g}$ of U6-Six3OS. For simultaneous knockdown, $1 \mu \mathrm{g}$ of U6-Six3 and $1 \mu \mathrm{g}$ of U6Six3OS were injected. For overexpression of Six 3 in combination with knockdown of Six3OS, retinas were electroporated with $1 \mu \mathrm{g}$ of pCAG-Six3 and $1 \mu \mathrm{g}$ of U6-Six3OS were injected. Finally, for overexpression of Six3OS in combination with knockdown of Six3, 1 g g of pCAGSix3OS and $1 \mu \mathrm{gg}$ of U6-Six3 were injected and electroporated.

\section{In situ hybridization}

For cryosections, untimed E14.5 and E16.5 embryos and P0.5 neonates were dissected, fixed overnight in $4 \%$ paraformaldehyde in PBS at $4^{\circ} \mathrm{C}$ and cryoprotected overnight in $30 \%$ sucrose/PBS at $4{ }^{\circ} \mathrm{C}$ before being embedded in OCT compound (Sakura, Torrance, CA, USA) on dry ice. Cryosections $(20 \mu \mathrm{m})$ were cut on a cryostat. Section ISH methodology was as previously described [32] with the exception that probe BC065087 was used and a Tyramide Signal Amplification system (TSA Plus, Perkin Elmer, NEL 744, Waltham, MA, USA) combined with an antidigoxigenin-HRP antibody (1:1, 000; Roche, Indianapolis, IN, USA). for fluorescent ISH. Fluorescent ISH sections were counterstained with DAPI. Fluorescent ISH samples were photographed on a Zeiss Meta 510 confocal microscope. Chromogenic images were visualized on a Zeiss Axioskop2 microscope.

\section{Immunohistochemistry}

For cryosections, electroporated eyes were harvested 21 days after electroporation, fixed for 1 hour in $4 \%$ paraformaldehyde in PBS at $4^{\circ} \mathrm{C}$ and cryoprotected overnight in $30 \%$ sucrose/PBS at $4^{\circ} \mathrm{C}$ before being embedded in OCT compound (Sakura) on dry ice. Cryosections $(20 \mu \mathrm{m})$ were cut on a cryostat. Retinal cryosections were immunostained as described except that sections were post fixed in 4\% paraformaldehyde for 5 minutes prior to blocking [21]. Samples were photographed on a Zeiss Meta 510 confocal microscope.

For cell marker analysis, dissociation and immunostaining were performed as described [34] except that retinas were harvested at P21. Samples were visualized and quantified on a Zeiss Axioskop2 microscope. To quantify the effects of Six 3 knockdown, retinas were electroporated with Six3 shRNA, harvested at P4.5, dissociated, and immunostained as described above with anti-Six 3 and detection with Alexa568 goat anti-guinea pig IgG and rabbit anti-GFP and detection with Alexa488 goat anti-rabbit. For Six 3 quantification, Six3OS overexpression and SixOS shRNA electroporated retinas were harvested at P5.5, dissociated and immunostained as described above with anti-Six 3 and detection with Alexa568 goat anti-guinea pig IgG and rabbit anti-GFP and detection with Alexa488 goat anti-rabbit. Samples were visualized on a Zeiss Axioskop2 microscope and signal intensity was quantified with Velocity 4.0 (Perkin Elmer) software by calculating the average signal intensity per cell and normalized to cell size.

\section{In situ hybridization and immunocytochemistry}

For Six3OS knockdown quantification, retinas were harvested at P4.5 and dissociated as described above. FISH was performed as described using TSA Plus Cyanine3 kit (1:125; Perkin Elmer, NEL 744) followed by staining as described (with rabbit anti-GFP and detection with Alexa488 goat anti rabbit). Samples were visualized and quantified as above. For all dissociations, nuclear DNA was visualized with DAPI counterstaining. Cell counts were analyzed using the two-tailed Student's $t$-test. A minimum of three retinas were counted for each construct examined using dissociated immunocytochemistry, with 100 to 300 GFP-positive cells per retina counted for each marker tested.

HeLa cell FISH followed by immunocytochemistry was performed as previously described [22] except that 20 cells were counted.

\section{Luciferase reporter assays}

NIH 3T3 cells were grown in DMEM supplemented with 10\% FCS. Cells were transfected with Fugene6 (Roche) per the manufacturer's instructions. Cells were transfected with $500 \mathrm{ng}$ of luciferase reporter construct and $50 \mathrm{ng}$ of the expression plasmids for Six 3 and Six3OS. Cells were harvested 2 days post-transfection. Luciferase was measured per manufacturer's instructions with the Dual-Luciferase Reporter System (Promega, E1910, Madison, WI, USA). pTK-Renilla (50 ng) was co-transfected to control for transfection efficiency.

\section{Synthesis of RNA probes for protein microarray}

BC065087 $(5 \mu \mathrm{g})$ was linearized with DraI, and $5 \mu \mathrm{g}$ of BM663835, BX115070, and BM451513 were linearized with NotI. Linearized DNA was then phenol-chloroform extracted, ethanol precipitated and resuspended in $10 \mu \mathrm{l}$ water. Probes were in vitro transcribed with T7 polymerase per manufacturer's instructions using the Riboprobe Combination system kit (Promega, P1405), spiking the reaction with $1 \mu \mathrm{l}$ of $5 \mathrm{mM}$ Cy5 labeled CTP (GE Healthcare, 25-8010-87, Piscataway, NJ, USA). The RNA probe was ethanol precipitated with $\mathrm{LiCl}$ and resuspended in $1 \mathrm{mM}$ EDTA.

\section{Protein microarray analysis}

Transcription factor/RNA binding protein chips were generated as previously described [37]. Protein chips were preblocked with Superblock Buffer (Thermo Scientific, 37516, Waltham, MA, USA) supplemented with $10 \mu \mathrm{g} \mathrm{ml}^{-1}$ sperm DNA, $2 \mathrm{mM} \mathrm{MgCl}_{2}, 2 \mathrm{mg} \mathrm{ml}^{-1}$ 
BSA for 1 hour at room temperature. RNA was hybridized at $250 \mathrm{nM}$ concentration in binding buffer (PBS supplemented with $2 \mathrm{mM} \mathrm{MgCl}_{2}, 2 \mathrm{mg} \mathrm{ml}^{-1} \mathrm{BSA}$ ) at room temperature for 1 hour. The slides were washed four times in TBST, dried and scanned by a GenePix 400B scanner. Data were analyzed with GenePix Pro 6.10 as previously described [46].

\section{RNA immunoprecipitation experiments}

HEK 293T cells were grown in DMEM supplemented with $10 \%$ FCS. Cells were transfected with Fugene6 (Roche) per the manufacturer's instructions. Ten million cells were transfected 24 hours post-plating with $5 \mu \mathrm{g}$ of pCAGIG-V5, pCAGIG-Six3-V5, pCAGIG Eya1-V5, pCAGIG Eya3-V5, pCAGIG Eya4-V5 or pCAGIG Ezh2V5, and pCAG-Six3OS. Cells were harvested 2 days post-transfection, lysed and precipitated essentially as previously described [11], except that $5 \mu \mathrm{g}$ anti-V5 antibody was used (1:5, 000; Invitrogen, R96025, Carlsbad, $\mathrm{CA}, \mathrm{USA}$ ) with $50 \mu \mathrm{l}$ protein A-agarose (Invitrogen, 15918-014) in each immunoprecipitation reaction. For each sample, $10 \%$ of total volume was set aside after lysis for RNA extraction and 5\% set aside for immunoblot analysis. After precipitation, $80 \%$ of the beads were resuspended in Trizol and 20\% were resuspended in Laemmle buffer. RNA was Trizol extracted and resuspended in $50 \mu \mathrm{l}$ of nuclease free water. RNA was then DNAse treated with Turbo DNA-free (Ambion, AM1907, Carlsbad, CA, USA) per manufacturer's instructions. RNA was quantified by quantitative RTPCR using Brilliant II SYBR Green QRT_PCR Master Mix (Agilent, 600825, Santa Clara, CA, USA) on a Roche LightCycler480. No-RT controls were simultaneously performed to demonstrate that signal was not from DNA contamination.

Expression of V5-tagged protein was confirmed by western analysis using anti-V5 antibody (1:10, 000; Invitrogen, R96025) dilution in 5\% milk in PBST, and detected with horse radish peroxidase goat anti-mouse IgG (1:10, 000; Santa Cruz, sc-2031, Santa Cruz, CA, USA) and ECL Western Blotting Detection System (GE Healthcare, RPN2132 Piscataway, NJ, USA) per the manufacturers' instructions.

Full details of all plasmids and antibodies used in this study are included in Additional File 9.

\section{Additional material}

Additional file 1: Six3OS is localized equally in the nucleus and cytoplasm. HeLa cells were transfected with Six3OS constructs and RNA location was analyzed by FISH followed by immunohistochemistry against the cytoplasmic S6 ribosomal protein. Cytoplasmic Six3OS RNA was identified by localization with $\mathbf{S 6}$ protein. The relative proportion of nuclear Six3OS, defined as FISH signal that did not colocalize with S6 protein, is indicated. $\mathrm{N}=20$ cells.
Additional file 2: Confirmation of shRNA-mediated knockdown of endogenous Six 3 and Six $30 S$ in developing retina. (A-E) A construct encoding either control hairpin, Six3 targeted hairpin or Six3OS targeted hairpin was electroporated in vivo, into P0.5 retina and harvested at P4.5, and dissociated, and immunocytochemistry against Six3 and GFP, or FISH against Six3OS was performed followed by immunostaining for GFP. GFPpositive cells were counted to analyze the fluorescence intensity for each cell that expressed (A) Six3 or (D) Six3OS. At least 100 GFP-positive cells from three different electroporated retinas were counted for each construct tested. Error bars represent standard error for at least three independent retinas. (A) $P<0.05$; (D) $P<0.05$. (B-E) Examples of dissociated cells positive for GFP and either Six3 protein or Six3OS RNA.

Additional file 3: Six3OS knockdown rescues changes in retinal cell morphology and position observed following overexpression of Six3. (A, B) Six3OS knockdown combined with Six3 overexpression rescues the effects observed on rod photoreceptor cell body position (A) and on photoreceptor outer segment length observed with Six3 overexpression (B).

Additional file 4: Summary of overexpression and knockdown data for Six 3 and Six 30 S. These results demonstrate that co-expression of Six3OS and Six3 rescues the phenotypes observed with Six3

overexpression except that the photoreceptors are displaced in the outer third of the outer nuclear layer. Simultaneous knockdown of Six3OS and Six3 results in a novel phenotype, fewer amacrine cells. Additionally, Six3OS overexpression rescues the phenotype of knockdown of Six3. However, expression of Six3 combined with knockdown of Six3OS results in an additive phenotype.

Additional file 5: Cellular levels of Six3 protein are not affected by overexpression or knockdown of Six3OS. (A) Overexpression of Six3OS at P0.5 does not affect Six3 protein levels when measured at P5.5. (B) shRNA-mediated knockdown at P0.5 of Six3OS does not affect Six 3 protein levels when measured at P5.5

Additional file 6: Autorepression of Six3 is not affected by Six3OS Transfection of CMV-Six3 together with the Six3-pro luciferase reporter into NIH 3 T3 led to $>70 \%$ reduction in luciferase expression. Cotransfection of CMV-Six3 and CAG-Six3OS with the Six3-pro luciferase reporter was not significantly different than CMV-Six3 alone.

Additional file 7: List of proteins that interact with the mouse and human forms of Six 30 S from the transcription factor/RNA binding protein microarray.

Additional file 8: V5 expression constructs are expressed in HEK 293T cells. $\alpha$ V5 western analysis demonstrating that Eya1-V5, Eya3-V5, Eya4-V5 and Ezh2-V5 are expressed.

Additional file 9: Supporting Information. Includes plasmid information, shRNA sequences and antibodies used.

\section{Abbreviations}

BSA: bovine serum albumin; DMEM: Dulbecco's modified Eagle's medium; E: embryonic day; FCS: fetal calf serum; FISH: fluorescent in situ hybridization; GFP: green fluorescent protein; ISH: in situ hybridization; IncOST: long noncoding opposite-strand transcript; IncRNA: long non-coding RNA; nCRNA: non-coding RNA; P: postnatal day; PBS: phosphate-buffered saline; PKC: protein kinase C; PRC2: Polycomb-repressive complex 2; RIP: RNA immunoprecipitation; shRNA: short hairpin RNA; TBST: Tris- buffered saline with Tween-20.

\section{Acknowledgements}

The authors thank Shiming Chen, Tomomi Shimogori, Jeremy Nathans, Wendy Yap and members of the Blackshaw lab for comments on the paper. This work was supported by a grant from the Whitehall Foundation to SB and a VNTP training grant to EP. SB is a WM Keck Foundation Distinguished Young Scholar in Medical Research.

\section{Author details}

'Department of Neuroscience, Neurology and Ophthalmology, Center for High-Throughput Biology and Institute for Cell Engineering, Johns Hopkins 
University School of Medicine, 733 N. Broadway Avenue, Baltimore, MD 21287, USA. ${ }^{2}$ Howard Hughes Medical Institute and Program in Epithelial Biology, Department of Dermatology, Stanford University School of Medicine, Stanford, CA 94305, USA. ${ }^{3}$ Department of Pharmacology and Center for High-Throughput Biology, Johns Hopkins University School of Medicine, 733 N. Broadway Avenue, Baltimore, MD 21287, USA.

\section{Authors' contributions}

NAR designed and performed experiments, analyzed the data and wrote the manuscript. EMP performed experiments. $\mathrm{HZ}$ analyzed the data. SB designed experiments, analyzed the data and wrote the manuscript. This manuscript has been seen and approved by all authors.

\section{Competing interests}

The authors declare that they have no competing interests.

Received: 28 May 2011 Accepted: 21 September 2011

Published: 21 September 2011

\section{References}

1. ENCODE Project Consortium, Birney E, Stamatoyannopoulos JA, Dutta A, Guigó R, Gingeras TR, Margulies EH, Weng Z, Snyder M, Dermitzakis ET, Thurman RE, Kuehn MS, Taylor CM, Neph S, Koch CM, Asthana S, Malhotra A, Adzhubei I, Greenbaum JA, Andrews RM, Flicek P, Boyle PJ, Cao H, Carter NP, Clelland GK, Davis S, Day N, Dhami P, Dillon SC, Dorschner $\mathrm{MO}$, et al: Identification and analysis of functional elements in $1 \%$ of the human genome by the ENCODE pilot project. Nature 2007, 447:799-816.

2. Mattick JS, Makunin IV: Non-coding RNA. Hum Mol Genet 2006, 15(Spec No 1):R17-29.

3. Prasanth KV, Spector DL: Eukaryotic regulatory RNAs: an answer to the 'genome complexity' conundrum. Genes Dev 2007, 21:11-42.

4. Guttman M, Amit I, Garber M, French C, Lin MF, Feldser D, Huarte M, Zuk O, Carey BW, Cassady JP, Cabili MN, Jaenisch R, Mikkelsen TS, Jacks T, Hacohen N, Bernstein BE, Kellis M, Regev A, Rinn JL, Lander ES: Chromatin signature reveals over a thousand highly conserved large non-coding RNAs in mammals. Nature 2009, 458:223-227.

5. Tochitani S, Hayashizaki Y: Nkx2.2 antisense RNA overexpression enhanced oligodendrocytic differentiation. Biochem Biophys Res Commun 2008, 372:691-696

6. Schwartz JC, Younger ST, Nguyen NB, Hardy DB, Monia BP, Corey DR, Janowski BA: Antisense transcripts are targets for activating small RNAs. Nat Struct Mol Biol 2008, 15:842-848.

7. Yu W, Gius D, Onyango P, Muldoon-Jacobs K, Karp J, Feinberg AP, Cui H: Epigenetic silencing of tumour suppressor gene p15 by its antisense RNA. Nature 2008, 451:202-206

8. Plath K, Mlynarczyk-Evans S, Nusinow DA, Panning B: Xist RNA and the mechanism of $X$ chromosome inactivation. Annu Rev Genet 2002, 36:233-278.

9. Pandey RR, Mondal T, Mohammad F, Enroth S, Redrup L, Komorowski J, Nagano T, Mancini-Dinardo D, Kanduri C: Kenq1ot1 antisense noncoding RNA mediates lineage-specific transcriptional silencing through chromatin-level regulation. Mol Cell 2008, 32:232-246.

10. Rinn JL, Kertesz M, Wang JK, Squazzo SL, Xu X, Brugmann SA, Goodnough LH, Helms JA, Farnham PJ, Segal E, Chang HY: Functional demarcation of active and silent chromatin domains in human HOX loci by noncoding RNAs. Cell 2007, 129:1311-1323.

11. Tsai MC, Manor O, Wan Y, Mosammaparast N, Wang JK, Lan F, Shi Y, Segal E, Chang HY: Long noncoding RNA as modular scaffold of histone modification complexes. Science 2010, 329:689-693.

12. Zhao J, Sun BK, Erwin JA, Song JJ, Lee JT: Polycomb proteins targeted by a short repeat RNA to the mouse X chromosome. Science 2008, 322:750-756

13. Lanz RB, McKenna NJ, Onate SA, Albrecht U, Wong J, Tsai SY, Tsai MJ, O'Malley BW: A steroid receptor coactivator, SRA, functions as an RNA and is present in an SRC-1 complex. Cell 1999, 97:17-27.

14. Feng J, Bi C, Clark BS, Mady R, Shah P, Kohtz JD: The Evf-2 noncoding RNA is transcribed from the Dlx-5/6 ultraconserved region and functions as a Dlx-2 transcriptional coactivator. Genes Dev 2006, 20:1470-1484.

15. Bond AM, Vangompel MJ, Sametsky EA, Clark MF, Savage JC, Disterhoft JF, Kohtz JD: Balanced gene regulation by an embryonic brain ncRNA is critical for adult hippocampal GABA circuitry. Nat Neurosci 2009, 12:1020-1027.

16. Cao X, Yeo G, Muotri AR, Kuwabara T, Gage FH: Noncoding RNAs in the mammalian central nervous system. Annu Rev Neurosci 2006, 29:77-103.

17. Dinger ME, Amaral PP, Mercer TR, Pang KC, Bruce SJ, Gardiner BB, AskarianAmiri ME, Ru K, Soldà G, Simons C, Sunkin SM, Crowe ML, Grimmond SM, Perkins AC, Mattick JS: Long noncoding RNAs in mouse embryonic stem cell pluripotency and differentiation. Genome Res 2008, 18:1433-1445.

18. Amaral PP, Dinger ME, Mercer TR, Mattick JS: The eukaryotic genome as an RNA machine. Science 2008, 319:1787-1789.

19. Chodroff RA, Goodstadt L, Sirey TM, Oliver PL, Davies KE, Green ED, Molnár Z, Ponting CP: Long noncoding RNA genes: conservation of sequence and brain expression among diverse amniotes. Genome Biol 2010, 11:R72.

20. Qureshi IA, Mattick JS, Mehler MF: Long non-coding RNAs in nervous system function and disease. Brain Res 2010, 1338:20-35.

21. Young TL, Matsuda T, Cepko CL: The noncoding RNA taurine upregulated gene 1 is required for differentiation of the murine retina. Curr Biol 2005, 15:501-512.

22. Rapicavoli NA, Poth EM, Blackshaw S: The long noncoding RNA RNCR2 directs mouse retinal cell specification. BMC Dev Biol 2010, 10:49.

23. Alfano G, Vitiello C, Caccioppoli C, Caramico T, Carola A, Szego MJ, Mclnnes RR, Auricchio A, Banfi S: Natural antisense transcripts associated with genes involved in eye development. Hum Mol Genet 2005, 14:913-923.

24. Rapicavoli NA, Blackshaw S: New meaning in the message: noncoding RNAs and their role in retinal development. Dev Dyn 2009, 238:2103-2114.

25. Seila AC, Calabrese JM, Levine SS, Yeo GW, Rahl PB, Flynn RA, Young RA, Sharp PA: Divergent transcription from active promoters. Science 2008, 322:1849-1851

26. Preker P, Nielsen J, Kammler S, Lykke-Andersen S, Christensen MS, Mapendano CK, Schierup MH, Jensen TH: RNA exosome depletion reveals transcription upstream of active human promoters. Science 2008, 322:1851-1854.

27. Core $L$, Waterfall JJ, Lis JT: Nascent RNA sequencing reveals widespread pausing and divergent initiation at human promoters. Science 2008, 322:1845-1848

28. Bonini NM, Leiserson WM, Benzer S: The eyes absent gene: genetic control of cell survival and differentiation in the developing Drosophila eye. Cell 1993, 72:379-395.

29. Pignoni F, Hu B, Zavitz KH, Xiao J, Garrity PA, Zipursky SL: The eyespecification proteins So and Eya form a complex and regulate multiple steps in Drosophila eye development. Cell 1997, 91:881-891.

30. Zhu CC, Dyer MA, Uchikawa M, Kondoh H, Lagutin OV, Oliver G: Six3mediated auto repression and eye development requires its interaction with members of the Groucho-related family of co-repressors. Development 2002, 129:2835-2849.

31. Lagutin OV, Zhu CC, Kobayashi D, Topczewski J, Shimamura K, Puelles L, Russell HR, McKinnon PJ, Solnica-Krezel L, Oliver G: Six3 repression of Wnt signaling in the anterior neuroectoderm is essential for vertebrate forebrain development. Genes Dev 2003, 17:368-379.

32. Blackshaw S, Harpavat S, Trimarchi J, Cai L, Huang H, Kuo WP, Weber G, Lee K, Fraioli RE, Cho SH, Yung R, Asch E, Ohno-Machado L, Wong WH, Cepko CL: Genomic analysis of mouse retinal development. PLoS Biol 2004, 2:E247.

33. Geng X, Lavado A, Lagutin OV, Liu W, Oliver G: Expression of Six3 Opposite Strand (Six3OS) during mouse embryonic development. Gene Expr Patterns 2007, 7:252-257.

34. Matsuda T, Cepko CL: Electroporation and RNA interference in the rodent retina in vivo and in vitro. Proc Natl Acad Sci USA 2004, 101:16-22.

35. Ørom UA, Derrien T, Beringer M, Gumireddy K, Gardini A, Bussotti G, Lai F, Zytnicki M, Notredame C, Huang Q, Guigo R, Shiekhattar R: Long noncoding RNAs with enhancer-like function in human cells. Cell 2010, 143:46-58.

36. Kim TK, Hemberg M, Gray JM, Costa AM, Bear DM, Wu J, Harmin DA, Laptewicz M, Barbara-Haley K, Kuersten S, Markenscoff-Papadimitriou E, Kuhl D, Bito H, Worley PF, Kreiman G, Greenberg ME: Widespread transcription at neuronal activity-regulated enhancers. Nature 2010, 465:182-187.

37. Hu S, Xie Z, Onishi A, Yu X, Jiang L, Lin J, Rho HS, Woodard C, Wang H, Jeong JS, Long S, He X, Wade H, Blackshaw S, Qian J, Zhu H: Profiling the 
human protein-DNA interactome reveals ERK2 as a transcriptional repressor of interferon signaling. Cell 2009, 139:610-622.

38. Jemc J, Rebay I: The eyes absent family of phosphotyrosine phosphatases: properties and roles in developmental regulation of transcription. Annu Rev Biochem 2007, 76:513-538.

39. Ørom UA, Derrien T, Beringer M, Gumireddy $K$, Gardini A, Bussotti G, Lai F, Zytnicki M, Notredame C, Huang Q, Guigo R, Shiekhattar R: Long noncoding RNAs with enhancer-like function in human cells. Cell 2010, 143:46-58.

40. Zhao J, Ohsumi TK, Kung JT, Ogawa Y, Grau DJ, Sarma K, Song JJ, Kingston RE, Borowsky M, Lee JT: Genome-wide identification of polycomb-associated RNAs by RIP-seq. Mol Cell 2010, 40:939-953.

41. Purcell P, Oliver G, Mardon G, Donner AL, Maas RL: Pax6-dependence of Six3, Eya1 and Dach1 expression during lens and nasal placode induction. Gene Expr Patterns 2005, 6:110-118.

42. Xu PX, Woo I, Her H, Beier DR, Maas RL: Mouse Eya homologues of the Drosophila eyes absent gene require Pax6 for expression in lens and nasal placode. Development 1997, 124:219-231.

43. Abe Y, Oka A, Mizuguchi M, Igarashi T, Ishikawa S, Aburatani H, Yokoyama S, Asahara H, Nagao K, Yamada M, Miyashita T: EYA4, deleted in a case with middle interhemispheric variant of holoprosencephaly, interacts with SIX3 both physically and functionally. Hum Mutat 2009, 30: E946-955.

44. Ravasi T, Suzuki H, Cannistraci CV, Katayama S, Bajic VB, Tan K, Akalin A, Schmeier S, Kanamori-Katayama M, Bertin N, Carninci P, Daub CO, Forrest AR, Gough J, Grimmond S, Han JH, Hashimoto T, Hide W, Hofmann O, Kamburov A, Kaur M, Kawaji H, Kubosaki A, Lassmann T, van Nimwegen E, MacPherson CR, Ogawa C, Radovanovic A, Schwartz A, Teasdale RD, et al: An atlas of combinatorial transcriptional regulation in mouse and man. Cell 2010, 140:744-752.

45. Mercer TR, Dinger ME, Sunkin SM, Mehler MF, Mattick JS: Specific expression of long noncoding RNAs in the mouse brain. Proc Natl Acad Sci USA 2008, 105:716-721.

46. Zhu J, Gopinath K, Murali A, Yi G, Hayward SD, Zhu H, Kao C: RNA-binding proteins that inhibit RNA virus infection. Proc Natl Acad Sci USA 2007, 104:3129-3134.

47. Siepel A, Bejerano G, Pedersen JS, Hinrichs AS, Hou M, Rosenbloom K, Clawson H, Spieth J, Hillier LW, Richards S, Weinstock GM, Wilson RK, Gibbs RA, Kent WJ, Miller W, Haussler D: Evolutionarily conserved elements in vertebrate, insect, worm, and yeast genomes. Genome Res 2005, 15:1034-1050.

doi:10.1186/1749-8104-6-32

Cite this article as: Rapicavoli et al:: The long noncoding RNA Six3OS acts in trans to regulate retinal development by modulating Six3 activity. Neural Development 2011 6:32.

\section{Submit your next manuscript to BioMed Central and take full advantage of:}

- Convenient online submission

- Thorough peer review

- No space constraints or color figure charges

- Immediate publication on acceptance

- Inclusion in PubMed, CAS, Scopus and Google Scholar

- Research which is freely available for redistribution

Submit your manuscript at www.biomedcentral.com/submit
Biomed Central 